\title{
Enhancement in Mechanical Properties of Polystyrene Filled with Carbon Nano-Particulates $\left(\mathrm{CNP}_{\mathrm{S}}\right)$
}

\author{
Ayman A. Aly ${ }^{*}$, Moustafa M. Mahmoud, Adel A. Omar \\ Department of Mechanical Engineering, Faculty of Engineering, Assiut University, Assiut, Egypt \\ Department of Mechanical Engineering, College of Engineering, Taif University, Taif, Saudi Arabia \\ Email: "draymanelnaggar@yahoo.com
}

Received March 24, 2012; revised April 30, 2012; accepted May 21, 2012

\begin{abstract}
The idea of adding reinforcing materials, or fillers, to polymers has been around for many decades. The reason for the creation of polymer composite materials came about due of the need for materials with specific properties for specific applications. For example, composite materials are unique in their ability to allow brittle and ductile materials to become softer and stronger. It is expected that good tribological properties can be obtained for polymers filled with nano-scale fillers. A soft plastic can become harder and stronger by the addition of a light weight high stiffness material. In the present work, the effect of adding different percentages of carbon nano-particulates to polystyrene (PS) on the mechanical properties of nano-composites produced was investigated. Based on the experimental observations, it was found that as the percentage of the carbon nano-particulates $\left(\mathrm{CNP}_{\mathrm{S}}\right)$ increased hardness increased and consequently friction coefficient remarkably decreased.
\end{abstract}

Keywords: Polymer Composites; Carbon Nano-Particulates $\left(\mathrm{CNP}_{\mathrm{S}}\right)$; Mechanical Properties; Tribological Properties

\section{Introduction}

In the past few decades, researchers and engineers interest has been shifted from monolithic materials to reinforced polymeric materials. These composite materials now dominate the aerospace, leisure, automotive, construction, and sporting industries [1].

Composite materials are typically made up of two materials, where one phase is the reinforcing phase, such as fibers, sheets, or particles and the other phase is the matrix material. The matrix material can be a metal, ceramic, or polymer, where the reinforcing material typically is a low density, high strength or toughness material [2].

A polymer nano-composite is defined as a composite material with a polymer matrix and filler particles that have at least one dimension less than $100 \mathrm{~nm}$. These engineering composites are desired due to their low density, high corrosion resistance, ease of fabrication and low cost [2-4].

Various kinds of polymers reinforced with metal particles have a wide range of industrial applications such as heaters, electrodes, actuators etc. [5]. When silica nanoparticles are added into a polymer matrix to form a composite, they play an important role in improving electrical, mechanical, and thermal properties of composites $[1,6]$. The inclusion of inorganic fillers into polymers for com-

\footnotetext{
${ }^{*}$ Corresponding author.
}

mercial applications is primarily aimed at the cost reduction and stiffness improvement [7].

The most commonly used filler materials for polymer composites are carbon fibers, carbon nano-tubes, carbon vapor grown nano-fibers, glass fibers, and metal or ceramic particulates. Glass fibers are added to polymeric materials to increase the specific strength and since both are relatively inert materials, allows for application in corrosive environments $[8,9]$.

Polymer composites can be fabricated by the incorporation of inorganic reinforcements into the polymer matrix. The properties of the resulting polymer composites depend on the characteristics, the dimensions, and the shapes of the inorganic fillers, and also on the interfacial bonding strength. It is proposed that with decreasing filler dimension or increasing filler content a significant improvement on contact area between the filler and matrix was carried out, and in turn this would greatly and effectively improve the transfer of the load between the fillers and the polymer matrix [8]. The inorganic nano-fillers, ranging from 1 to $50 \mathrm{~nm}$, were successfully incorporated into the polymeric matrix to strengthen and improve the ductile polymer to be more stiff and resistant for abrasion $[9,10]$.

The determination of the mechanical properties of composite materials has proven challenging and remains a subject of debate. There are several methods that can be 
employed to theoretically determine composite properties. These methods include; the rule of mixtures, the inverse rule of mixtures, and the modified rule of mixtures [11]. The previous rules estimate properties only by the composition of the composite, but mechanical testing is necessary, because the mechanical properties are dependent on many factors. The full potential of the material isn't fully understood until samples can be made and mechanical tests can be performed.

The mechanical properties of carbon nano-tubes composites are largely dependent upon the quantity of CNTs in the system, the dispersion and alignment of the tubes, and the interfacial bonding between the carbon nanotubes and the matrix [1]. The ability to determine the precise amount of carbon nano-tubes needed to increase the stiffness is just the beginning. Therefore, there is a need for these carbon nano-tubes to be dispersed, aligned, and have favorable interactions with the matrix material.

There are several different methods for dispersing carbon nano particles, and the determination of the ideal method proves challenging. These methods utilize polymers, surfactants, acids, or a combination of several different materials to disperse carbon nano-tubes [12-14]. Several of these methods tend to utilize hazardous materials and lengthy procedures to produce the desired result, while others require less dangerous materials with shorter durations to produce a similar result [5,6,12-24]. Therefore, these less dangerous methods used to dispersed carbon nano-tube may not be thought of as "ideal methods". Typically all of the methods utilize some degree of sonification, from a few minutes to several hours, to initially mechanically disperse the carbon nano-tubes. This method of mechanical dispersion in conjunction with the use of both acetone and toluene surface active agents to reduce the van der Waals forces, provided that, the dispersing agent can separate the carbon nano-tubes to prevent re-aggregation $[21,22]$.

Due to the interactions of the polymer chains with the supporting surface and the air interface, the thinner films required for such applications have distinctly different properties than those of the well-defined bulk systems.

Many bulk polymer properties have been well defined in the recent literature [23]. In addition, theories that offer reasoning for changes in these bulk properties with temperature, pressure, etc. have been developed. Focus has been shifted in the past decade to polymers in thin film geometries. These systems remain obscure to polymer scientists.

Thin films have become ubiquitous in the polymer industry. Fueled by the microelectronics industry and its need for miniature parts, polymer applications have become more demanding. Polymers in these environments have been tested and modeled in laboratories around the world: from universities to automobile companies, research surrounding thin films is quickly growing [8].
Two main areas of research have emerged that cover thin polymer films. The first, free-standing films, investigates thin films unattached to a substrate. The main concern in this field is how the air-polymer interface affects the behavior of the polymer as the film decreases in thickness. The second, polymer films on substrates, focuses on the interactions at the polymer-substrate interface. Both research fields have reported data and offered explanations for what has been observed.

The present paper aims to study the effect of adding different percentages of carbon nano-particulates $\left(\mathrm{CNP}_{\mathrm{S}}\right)$ to polystyrene (PS) on the mechanical properties of nanocomposites produced. Current research has focused on the task of defining thin film behavior when the polystyrene $(\mathrm{PS})$ mixed $\left(\mathrm{CNP}_{\mathrm{S}}\right)$ is cast on a surface by using the spin coating method.

\section{Experimental Procedures}

\subsection{Materials}

Polymer: Polystyrene.

Reinforcement: Carbon nano-particulates $\left(\mathrm{CNP}_{\mathrm{S}}\right)$ clusters.

Solvent: Toluene.

\subsection{Spin-Coating Method}

Many techniques needed to be developed to create and monitor these new thin film systems. An accurate method for producing thin polymer films was the first objective of this research. The proposed solution to the problem was spin-coating.

First a polymer solution was made and was pipetted onto the desired surface. Next, the substrate was "accelerated to a desired rotation rate". Spinning continued until an equilibrium film thickness was reached. This was followed by annealing to alleviate radial orientation and eliminate any remaining solvent.

Several variables can control the film thickness of the final product. Extract looked at some parameters of spincoating experimental are in [17]. The solvent used to make the solution does affect the final thickness of the film. Different viscosity and solubility can make PMMA films cast from a cyclohexane solution twice as thick as those cast from a toluene solution. The research also showed that thickness increased as spin speed decreased as would be expected. The amount of solution applied to the wafer did not affect the thickness as long as there was enough present to cover the surface. Any excess was simply flung off the surface by centripetal forces [17].

Because thin films are used in so many applications, Bornside, Macosko, and Scriven developed a model for achieving a desired film thickness [18]. They divided spin coating into the four stages of deposition, spin-up, spin-off, and evaporation (Figure 1). By taking both the force of 


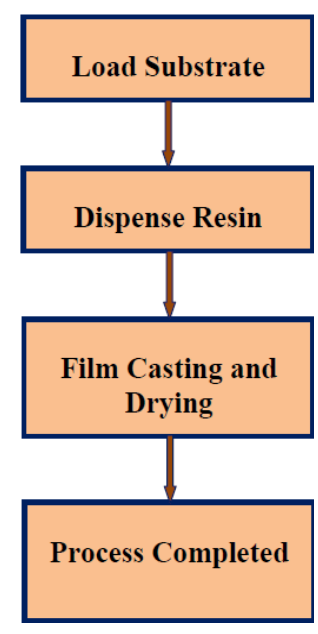

Figure 1. Stages of spin-coating.

spinning and the concentration-controlled evaporation into account, these researchers were able to predict film thickness. This model was extremely useful because it included the surface chemistry and the type of polymer used.

Because of the dependable nature of the method and the ease of use, spin coating is frequently used to create polymer thin films.

Solutions in toluene were prepared at $0.2 \%, 0.5 \%$, $0.7 \%$, and $1.0 \%$ by weight of $\mathrm{CNP}_{\mathrm{S}}$.

The silicon wafers were positioned on the spin coater and several drops of solution were placed on the wafer. Immediately, each sample began rotating at a constant speed to acquire the desired film thickness (2500 rpm). The samples were spun for one minute.

\subsection{Test Rig}

Initially the test rig built on the idea to utilize the possibilities of a small lathe machine such as the different cutting speeds and the automatic movement of the carriage. The used lathe machine is suitable for laboratory applications. In fact, the machine tool can expand its function with various accessories to modify the test nature.

For measuring the friction and wear resistance a test rig was built. The test specimen assembly was carried on the compound cross slide of the lathe, which automatically operated for positioning purposes in the direction of adhesion, driven by controlled speeds. The test specimen was mounted on a platen supported on the tool post and restrained by a load cell, which senses tangential force on the test surface in the direction of sliding. The details of the test rig are shown in Figure 2. The indenter, used in experiments, was a spherical and hardened steel ball having diameter of $1.588 \mathrm{~mm}$, (see Figure 2). The friction force was measured by the deflection of the load cell. The ratio of the friction force to the normal load was considered as friction coefficient. The load was applied

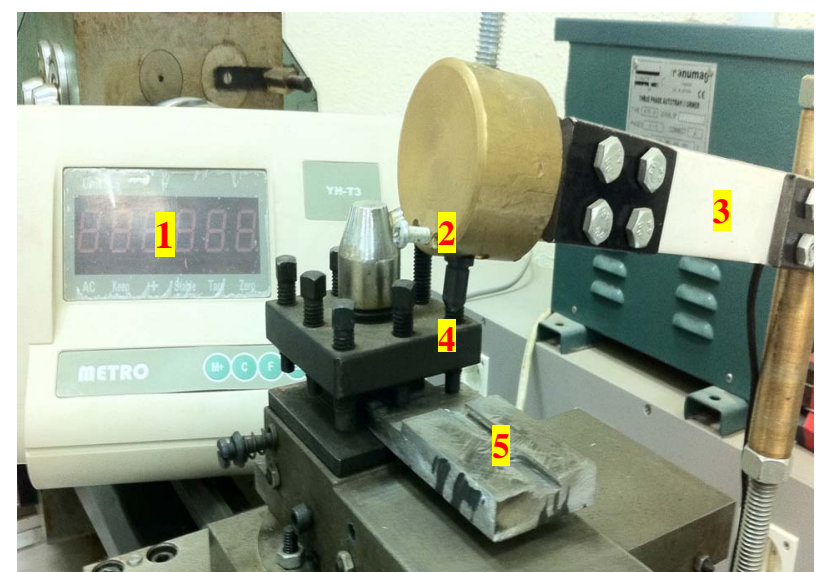

(a)

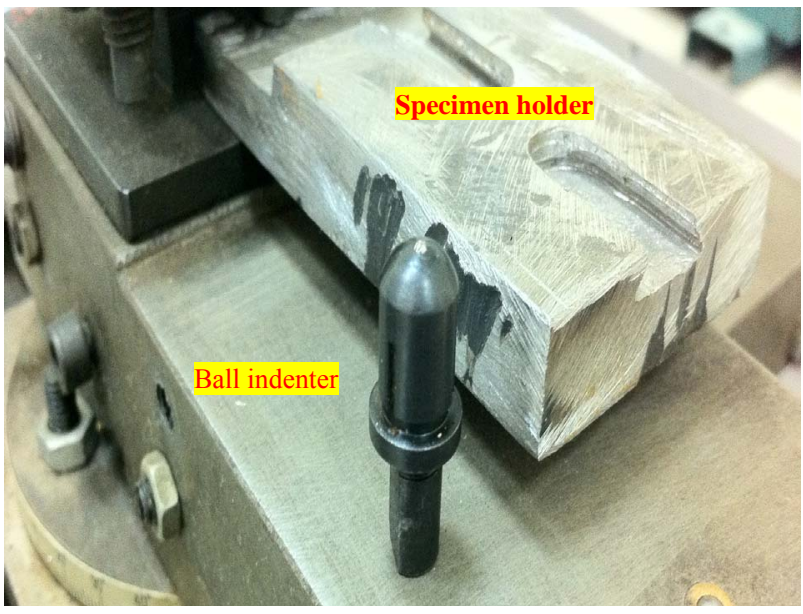

(b)

Figure 2. (a)-(b) used test rig (1. Screen; 2. Indenter Holder; 3. Load Cell; 4. Ball Indenter; 5. Specimen Holder).

by weights. The test speed was nearly controlled by automatically turning the power screw feeding the indenter in the adhesion direction. The adhesion velocity was 0.05 $\mathrm{mm} / \mathrm{s}$. All measurements were performed at $28^{\circ} \mathrm{C} \pm 2^{\circ} \mathrm{C}$ and $50 \% \pm 10 \%$ humidity.

\section{Results and Discussion}

The Vickers test is often easier to use than other hardness tests since the required calculations are independent of the size of the indenter, and the indenter can be used for all materials irrespective of hardness. The basic principle, as with all common measures of hardness, is to observe the questioned material's ability to resist plastic deformation from a standard source.

The unit of hardness given by the test is known as the Vickers Pyramid Number (HV) or Diamond Pyramid Hardness (DPH). The hardness number is determined by the load over the surface area of the indentation and not the area normal to the force, and is therefore not a pressure.

Accordingly, loads of various magnitudes are applied 
to a flat surface, depending on the hardness of the material to be measured. The HV number is then determined by the ratio $\mathrm{F} / \mathrm{A}$ where $\mathrm{F}$ is the force applied to the diamond in kilograms-force and A is the surface area of the resulting indentation in square millimeters.

Figure 3 represents the effect of carbon nano-particulates content added on the micro-hardness of composite produced. It obvious that the micro-hardness increased with the increase in $\mathrm{CNP}_{\mathrm{S}}$ content and this is attributed primarily to the presence of nano-size reinforcement carbon particulates. This result agrees with the previous fact that addition of small amount of $\mathrm{CNP}_{\mathrm{S}}(<3$ $\mathrm{wt} \%$ ) to a matrix system can increase mechanical properties without compromising the processability of the composite [25]. The micro-hardness increased nearly linearly with the $\mathrm{CNP}_{\mathrm{S}}$ content at $\geq 0.2 \mathrm{wt} \%$. This means that the maximum utilization of the properties of carbon $\mathrm{CNP}_{\mathrm{S}}$ was achieved throughout its uniform dispersion and good wetting within the polystyrene matrix.

Figure 4 represents the relationship between estimated tensile strength and $\mathrm{CNP}_{\mathrm{S}}$ content. It is clear that the estimated tensile strength increased with the increase in carbon content. A drastic improvement in the mechanical properties of CNTs/polymer composites already mentioned in many researches [26-30]. These researches have shown that many factors play an important role and influence the interface affecting therefore properties in carbon nanotube composites. Thus, interesting properties are obtained, depending on the conditions used in the synthesis, dispersion quality and raw material features, showing that, in some cases, it is possible to obtain some interesting properties using carbon nanotubes as-synthesized. In addition, the good interfacial bonding between carbon nanotubes (CNTs) and Polymer matrix could one of these reasons which are responsible for this higher values of strength in this present work.

The effect of the $\mathrm{CNP}_{\mathrm{S}}$ content on the friction coefficient of composites is shown in Figure 5 at different applied loads (4, 5 and $6 \mathrm{~N})$. Generally, the figure shows scattering values for the frictional behavior of PS nanocomposites containing different $\mathrm{CNP}_{\mathrm{S}}$ contents.

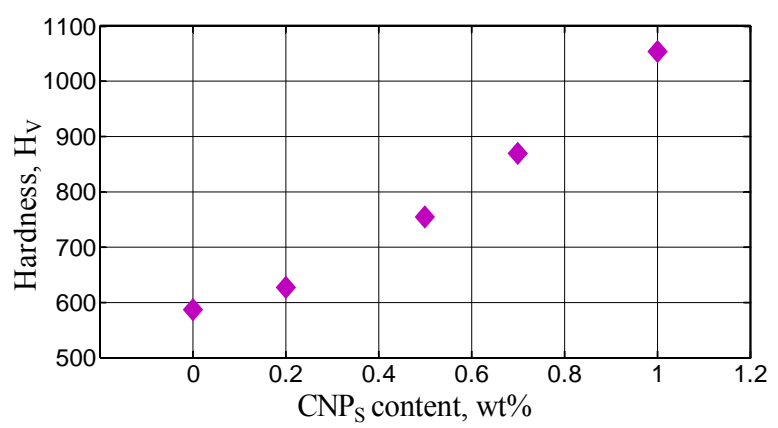

Figure 3. Effect of carbon nano-particulates content on the micro-hardness of produced composite.

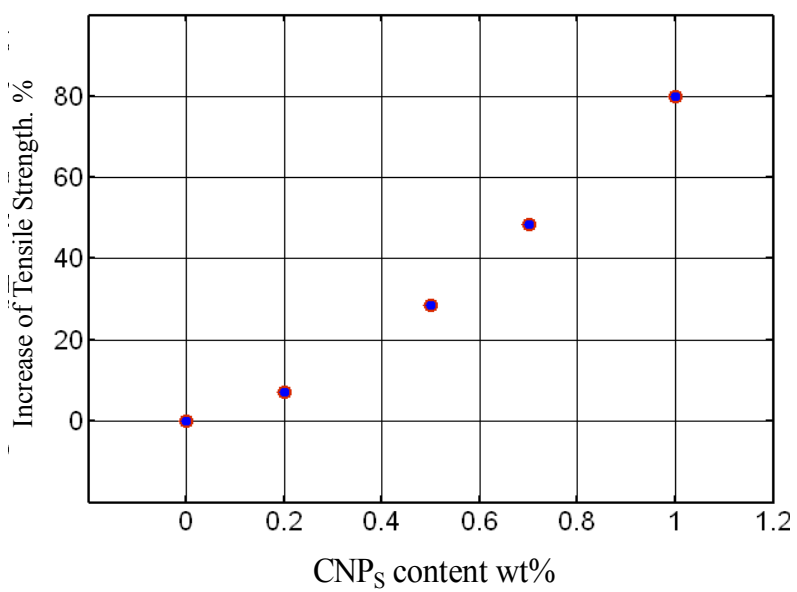

Figure 4. Effect of carbon nano-particulates content on the tensile strength of produced composite.

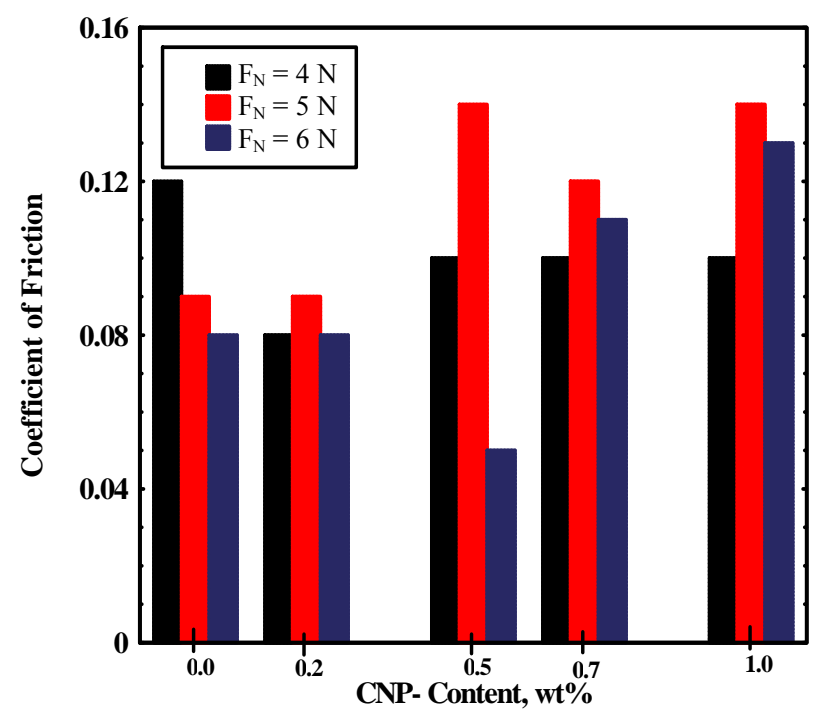

Figure 5. Friction coefficient of the carbon nano-particulates-PS composites.

It is clear that there are two different behaviors in the figure; one of them belongs to the unfilled specimens and the other concerning with filled specimens. The unfilled specimen exhibits a continuous decrease in the coefficient of friction with increasing normal load as a result of the frictional heating that reduced the shear strength of the PS specimens. Moreover, the topography of the surface becomes smoother with increasing the load causing a decrease in the values of friction. Whereas the second trend which concerning with the carbon nano-particulates filled PS based composites shows a variation of friction coefficient with increasing normal load. Friction coefficient of PS samples filled by carbon nano-particulates with different weight contents is shown in the previous Figure too. PS composites containing carbon nano-particulates of $0.5 \mathrm{wt} \%$ showed the smallest coefficient of friction at applied load of $6 \mathrm{~N}$ while the maximum values 
always displayed at applied load of $5 \mathrm{~N}$. The increase in the coefficient of friction during adhesion is attributed to increasing plowing of the coating by the indenter with increasing normal load but the abrupt decrease of friction at applied load of $6 \mathrm{~N}$ may be attributed to the direct contact with the carbon nano-particulates which its nature as a solid lubricant.

The dependence of PS wear scar width on carbon nanoparticulates content at different applied normal loads and constant speed is exhibited in Figure 6. It is shown that the wear scar width increased up to maximum value then decreased with increasing normal load and carbon nanoparticulates content. The increase in wear is attributed to the increase in the contact area with increasing normal load. The decrease in the width of wear scar after the maximum is possibly due to the plasticization at loads higher than a critical value. This means there is a direct contact with the hardened carbon nano-particulates causing a high wear resistance appears in small wear scars. It can relate this interpretation with the directly proportional relationship of hardness and carbon nano-particulates content as shown in Figure 6.

When the samples were examined following testing, it was apparent from measurements of the width of the wear tracks that considerable macroscopic plastic deformation had taken place. There was evidence of roughening and galling of the hardened steel ball as shown in microscopic image (Figures 7 and 8). It was shown that the width of the wear tracks on the contact surface of the unfilled PS specimens under different normal loads is measured. Moreover the width of wear tracks can express about the amount of the plastic deformation localization in the wear tracks, see Figures 7 and 8. This amount decreased with

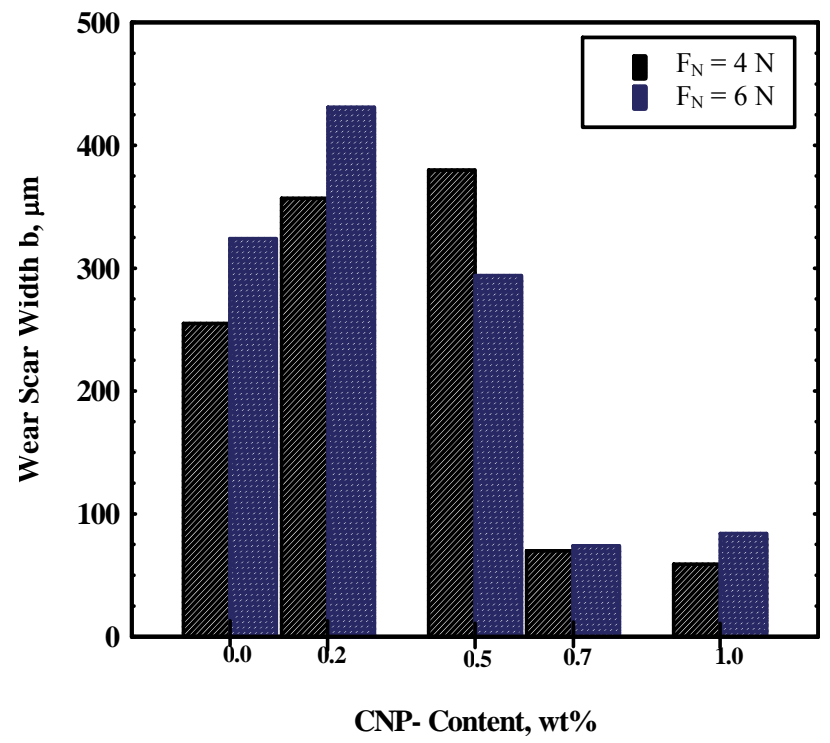

Figure 6. Dependence of PS wear scar width on carbon nano-particulates content.

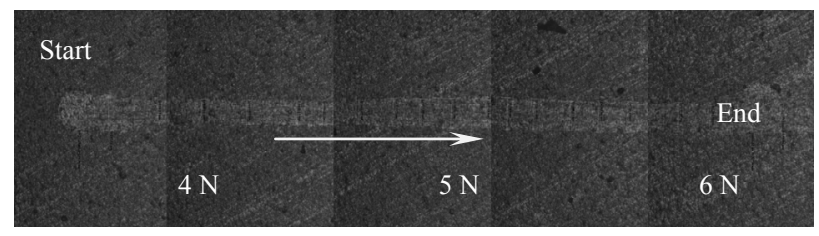

Figure 7. Panorama picture of a wear track on unfilled PS specimens at different normal loads and constant speed 0.05 $\mathrm{mm} / \mathrm{s}$.

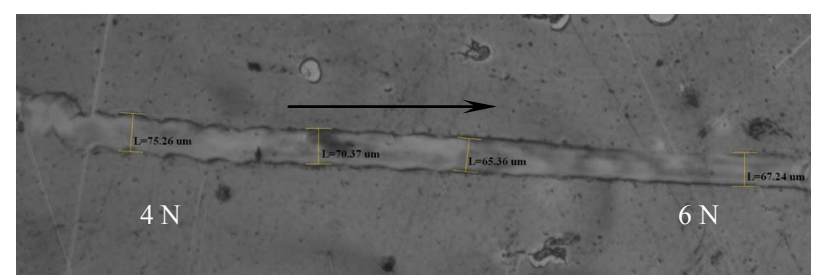

Figure 8. Wear track on 0.7 wt \% carbon nano-particulates filled PS specimens at normal loads 4 and $6 \mathrm{~N}$ and constant speed $0.05 \mathrm{~mm} / \mathrm{s}$.

increasing the $\mathrm{CNP}_{\mathrm{S}}$ content.

\section{Conclusion}

In this work, we produced the composite material (filled with Nanoparticles). A challenging issue that improving the tribological properties of the produced material. In the produced composite material, the micro-hardness increased nearly linearly with the $\mathrm{CNP}_{\mathrm{S}}$ content at $\geq 0.2 \%$. This means that the maximum utilization of the properties of $\mathrm{CNP}_{\mathrm{S}}$ was achieved throughout its uniform dispersion and good wetting within the polystyrene matrix. The estimated tensile strength increased with the increase in carbon content. This is attributed to the reinforcement effect of $\mathrm{CNP}_{\mathrm{S}}$ in the polystyrene matrix which consequently improves the mechanical properties in general. The friction and wear properties of PS-carbon nano-particulates composites were promising. The carbon nanoparticulates filled PS based composites shows a variation of friction coefficient with increasing normal load. PS composites containing $\mathrm{CNP}_{\mathrm{S}}$ of $0.5 \mathrm{wt} \%$ showed the smallest coefficient of friction at applied load of $6 \mathrm{~N}$ while the maximum values always displayed at applied load of $5 \mathrm{~N}$. Generally the values of coefficient of friction are low enough to have many practical applications. $\mathrm{CNP}_{\mathrm{S}}$-PS composites, particularly 0.7 and $1 \mathrm{wt} \%$, exhibited high wear resistance owing to the possibly plasticization which occurred at loads higher than a critical value and the direct contact with hardened $\mathrm{CNP}_{\mathrm{S}}$.

\section{Acknowledgements}

The authors would like to express their sincere gratitude to Taif University for its fully funding this research project (project number 1171/1431). 


\section{REFERENCES}

[1] C. L. E. Nielsen and R. F. Landel, "Mechanical Properties of Polymers and Composites," 2nd Edition, Marcel Deckker, New York, 1994.

[2] S. Nikkeshi, M. Kudo and T. Masuko, "Dynamic Viscoelastic Properties and Thermal Properties of Powder-Epoxy Resin Composites," Journal of Applied Polymer Science, Vol. 69, No. 13, 1998, pp. 2593-2598. doi:10.1002/(SICI)1097-4628(19980926)69:13<2593::AI D-APP9>3.0.CO;2-5

[3] K. Zhu and S. Schmauder, "Prediction of the Failure Properties of Short Fiber Reinforced Composites with Metal and Polymer Matrix," Computational Materials Science, Vol. 28, No. 3-4, 2003, pp. 743-748. doi:10.1016/j.commatsci.2003.08.028

[4] I. H. Tavman, "Thermal and Mechanical Properties of Copper Powder Filled Polyethylene Composites," Powder Technology, Vol. 91, No. 1, 1997, pp. 63-67. doi:10.1016/S0032-5910(96)03247-0

[5] T. Ahmad and O. Mamat, "The Development and Characterization of Zirconia-Silica Sand Nanoparticles Composites," World Journal of Nano Science and Engineering, Vol. 1, No. 1, 2011, pp. 7-14. doi:10.4236/wjnse.2011.11002

[6] S. T. Peters, "Handbook of Composites," 2nd Edition, Chapman and Hall, London, 1998.

[7] R. N. Rothon, "Mineral Fillers in Thermoplastics I Raw Materials and Processing," In: J. Jancar, Ed., Advances in Polymer Science, Vol. 139, Springer, Berlin, 1999, p. 67.

[8] M. Sumita, T. Shizuma, K. Miyasaka and K. Ishikawa, "Effect of Reducible Properties of Temperature, Rate of Strain, and Filler Content on the Tensile Yield Stress of nylon 6 Composites Filled with Ultrafine Particles," Journal of Macromolecular Science, Part B: Physics, Vol. 22, No. 4, 1983, pp. 601-618. doi: $10.1080 / 00222348308224779$

[9] P. Ayak, S. K. Sahoo, A. Behera, P. K. Nanda, P. L. Nayak and B. C. Guru, "Synthesis and Characterization of Soy Protin Isolate/MMT Nanocomposite Film for the Control Release of the Drug Ofloxacin," World Journal of Nano Science and Engineering, Vol. 1, No. 2, 2011, pp. 27-36. doi:10.4236/wjnse.2011.12005

[10] A. A. Aly, E.-S. B. Zeidan, A. A. Alshennawy, A. A. El-Masry and W. A. Wasel, "Friction and Wear of Polymer Composites Filled by Nano-Particles: A Review," World Journal of Nano Science and Engineering, Vol. 2, No. 1, 2012, pp. 32-39.

[11] M. C. Kuo, C. M. Tsai, J. C Huang and M. Chen, "Peek Composites Reinforced by Nano-Sized $\mathrm{SiO}_{2}$ and $\mathrm{Al}_{2} \mathrm{O}_{3}$ Particulates Materials," Chemistry and Physics, Vol. 90, No. 1, 2005, pp. 185-195.

[12] T. E. Attwood, P. C. Dawson, J. L. Freeman, L. R. J. Hoy, J. B. Rose and P. A. Staniland, "Synthesis and Properties of Polyaryletherketones," Polymer, Vol. 22, No. 8, 1981, pp. 1096-1103. doi:10.1016/0032-3861(81)90299-8

[13] P. K. Goyal, Y. S. Negi and A. N. Tiwari, "Preparation of High Performance Composites Based on Aluminum Nitride/Poly(Ether-Ether-Ketone) and Their Properties," Euro- pean Polymer Journal, Vol. 41, No. 9, 2005, pp. 20342044. doi:10.1016/j.eurpolymj.2005.04.009

[14] P. Cassagnau, "Payne Effect and Shear Elasticity of Silica-Filled Polymers in Concentrated Solutions and in Molten State," Polymer, Vol. 44, No. 8, 2003, pp. 2455 2462. doi:10.1016/S0032-3861(03)00094-6

[15] Y. H. Lai, M. C. Kuo, J. C. Huang and M. Chen, "Thermomechanical Properties of Nanosilica Reinforced PEEK Composites," Key Engineering Materials, Vol. 351, No. 15, 2007, pp. 15-20. doi:10.4028/www.scientific.net/KEM.351.15

[16] Q. H. Wang, Q. J. Xue, W. M. Liu and J. M. Chen, "The Friction and Wear Characteristics of Nanometer SiC and Polytetrafluoroethylene Filled Polyetheretherketone," Wear, Vol. 243, No. 1-2, 2000, pp. 140-146. doi:10.1016/S0043-1648(00)00432-4

[17] C. J. Schwartz and S. Bahdur, "Studies on the Tribological Behavior and Transfer Film-Counterface Bond Strength for Polyphenylene Sulfide Filled with Nanoscale Alumina Particles," Wear, Vol. 237, No. 2, 2000, pp. 261-273. doi:10.1016/S0043-1648(99)00345-2

[18] E. Reynaud, C. Gauthier and J. Perez, "Nanophases in Polymers," Revue de Metallurgie, Vol. 98, No. 1, 1999, pp. 169-176.

[19] Q. H. Wang, Q. J. Xue and W. C. Shen, "The Friction and Wear Properties of Nanometre $\mathrm{SiO}_{2}$ Filled Polyetheretherketone," Tribology International, Vol. 30, No. 3, 1997, pp.193-197. doi:10.1016/S0301-679X(96)00042-4

[20] M. Q. Zhang, M. Z. Rong, S. L. Yu, B. Wetzel and K. Friedrich, "Improvement of Tribological Performance of Epoxy by the Addition of Irradiation Crafted Nano-Inorganic Particles," Macromolecular Materials and Engineering, Vol. 287, No. 2, 2002, pp. 111-115. doi:10.1002/1439-2054(20020201)287:2<111::AID-MA ME111>3.0.CO;2-I

[21] F. Li, K. Hu and J. Li, "The Friction and Wear Characteristics of Nanometer ZnO Filled Polytetrafluoroethylene," Wear, Vol. 249, No. 10-11, 2002, pp. 877-882. doi:10.1016/S0043-1648(01)00816-X

[22] W. G. Sawyer, K. D. Freudenberg, P. Bhimaraj and L. S. Schadler, "A Study on the Friction and Wear Behavior of PTFE Filled with Alumina Nanoparticles," Wear, Vol. 254, No. 5, 2003, pp. 573-580.

[23] A. A. Ayman, E. B. Zeidan, A. M. Hamed and W. Y. Ali, "Effect of Heat Treatment on the Abrasion Resistance of Thermoplastic Polymers," EGTRIB Journal of the Egyptian Society of Tribology, Vol. 7, No. 4, 2010, pp. 52-64.

[24] A. Hoshino, K. Fujioka, T. Oku, S. Nakamura, M. Suga, Y. Yamaguchi, K. Suzuki and M. Yasuhara, "Quantum Dots Targeted to the Assigned Organelle in Living Cells," Microbiology and Immunology, Vol. 48, No. 12, 2004, pp. 985-994.

[25] Y. X. Zhou, F. Pervin, S. Jeelani and P. K. Mallik, "Improvement in Mechanical Properties of Carbon FabricEpoxy Composite Using Carbon Nanofibers," Journal of Materials Processing Technology, Vol. 198, No. 1-3, 2008, pp. 445-453. doi:10.1016/j.jmatprotec.2007.07.028

[26] A. L. Martínez-Hernández, C. Velasco-Santos and V. M. 
Castaño, "Carbon Nanotubes Composites: Processing, Grafting and Mechanical and Thermal Properties," Current Nanoscience, Vol. 6, No. 1, 2010, pp. 12-39. doi: $10.2174 / 157341310790226270$

[27] D. Srivastava and C. Wei, "Nanomechanics of Carbon Nanotubes and Composites," Applied Mechanics Reviews, Vol. 56, No. 2, 2003, p. 215. doi:10.1115/1.1538625

[28] A. Plaseied and A. Fatemi, "Mechanical Properties and Deformation Behavior of a Carbon Nanofiber Polymer Composite Material," Proceedings of MN 2006 Multifunctional Nanocomposites, Honolulu, 20-22 September
2006, pp. 203-208.

[29] U. A. Joshi, P. Joshi, S. P. Harsha and S. C. Sharma, "Evaluation of the Mechanical Properties of Carbon Nanotube Based Composites by Finite Element Analysis," International Journal of Engineering Science and Technology, Vol. 2, No. 5, 2010, pp 1098-1107.

[30] B. Zhao, J. Wang, Z. J. Li, P. Liu, D. Chen and Y. F. Zhang, "Mechanical Strength Improvement of Polypropylene Threads Modified by PVA/CNT Composite Coatings," Materials Letters, Vol. 62, No. 28, 2008, pp. 43804382. doi:10.1016/j.matlet.2008.07.037 